\title{
A TECNOLOGIA DA INFORMAÇÃO E SUA UTILIZAÇÃO NA COMPOSIÇÃO DE JOGOS DIGITAIS EDUCACIONAIS
}

\author{
INFORMATION TECHNOLOGY AND ITS USE IN THE COMPOSITION \\ OF EDUCATIONAL DIGITAL GAMES
}

José henrique Basaglia - ze_pirangi@hotmail.com Bruno Assirati - assirati_@hotmail.com Filipe Augusto Salla - sallafilipe@ gmail.com Faculdade São Luís - Jaboticabal - SP - Brasil

DOI: 10.31510/infa.v15i1.342

\section{RESUMO}

$\mathrm{O}$ advento da era da informação trouxe consigo certo grau de complexidade que foi tomando conta do cenário das empresas ao longo do tempo, sendo cada vez mais necessária a presença da tecnologia. Os jogos de computador têm evoluído de forma a trazer uma maior experiência de interatividade aos usuários. Atualmente, alguns jogos já possibilitam formas de interação com ambientes virtuais criados a partir de ambientes reais ou por meio da Realidade Aumentada. Esses novos recursos fornecem aos usuários uma resiginificação dos espaços onde agora passam a participar ativamente pelo jogo. Sendo assim este trabalho tem como objetivo explanar a utilização da tecnologia da informação gerenciada aos jogos digitais educacionais. Os jogos digitais aparecem nesse contexto como um recurso didático que contém características que podem trazer uma série de benefícios para as práticas de ensino e aprendizagem.

Palavras Chave: Tecnologia da Informação. Jogos Digitais. Educação.

\begin{abstract}
The advent of the age of information brought with it a certain level of complexity that took care of the business scenario over time, being more and more necessary of the technology presence. The computer games has evolved bringinng more interactive experience for its users. Nowaday, many games already have interaction with vitual enviroment made from real enviroment or by augmented reality. These new resouces provide to its users a new redetermination of space where they are now participate activily by the game. Therefore this article aims to explain the use of the information technology managed to the educational digital games. The digital games shows up into this context as a didactic resource that contains characteristics that can bring a series of benefits for teaching and learning practices.
\end{abstract}

Keywords: Information Technology. Digital Games.Education. 


\section{INTRODUÇÃO}

Nota-se que ao longo dos anos uma transformação no cotidiano das pessoas, a Globalização permitiu uma nova maneira de vivermos e solucionar problemas, um mundo mais moderno, dinâmico e interativo.

O uso das tecnologias na sala de aula nos faz pensar em uma mudança na maneira de compreender o processo ensino aprendizagem, pois nas últimas décadas presenciou-se uma evolução no mundo da tecnologia, comunicação, revolucionando o dia a dia das pessoas nos dias atuais.

É de muita relevância que a escola esteja aberta a novas realidades, onde alunos e professores assimilem uma abordagem tecnológica e vivenciem a atualidade, com o uso das novas ferramentas, como computadores com acesso à internet, mídias, entre muitas outras ferramentas tecnológicas.

Existem no mercado sistemas informatizados especializados em gestão educacional.

Eles têm como princípio integrar todas as informações que dizem respeito à escola. Todo esse conjunto de informações costuma circular numa rede interna, onde somente usuários autorizados e com seus níveis de acesso podem ter acesso a essas informações (MORAN,2003, p. 18)

As Tecnologias da Informação e Comunicação (TICs)são a nova realidade do século XXI e vem se destacando cada vez mais, assim que surgem novas ferramentas tecnológicas, novos recursos que facilitam a vida das pessoas, com essa apresentação de mudanças e transformações a escola surge no momento em que media e transmite o conhecimento de uma forma reflexiva e prática, surgindo uma nova abordagem de transmitir o processo ensino aprendizagem, buscando o contexto do aluno na sua realidade.

A utilização de recursos informatizados, pode potencializar o desenvolvimento dessas diversas competências, possibilitando uma reestruturação do modo de relacionamento entre aluno professor, pois o processo de desenvolvimento atende aos vários interesses individuais e coletivos.

Os computadores estão cada vez mais presentes na vida cotidiana da nossa sociedade. Sua presença cultural aumenta a cada dia e, com a chegada nas escolas, é necessário refletir sobre o que se espera desta tecnologia como recurso pedagógico para ser utilizado no processo de ensino-aprendizagem. 
A diversão, usando o computador como ferramenta, tem se tornado uma forte tendência, incentivada por recursos tecnológicos cada vez mais sofisticados e acessíveis. O jogo educativo deve proporcionar um ambiente crítico, fazendo com que o aluno se sensibilize para a construção de seu conhecimento com oportunidades prazerosas para o desenvolvimento de suas cognições.

A fórmula computador mais jogo se torna eficiente, pois associa a riqueza dos jogos educativos com o poder de atração dos computadores. E, como consequência desta associação, teremos os jogos educacionais computadorizados, onde o computador será usado de forma lúdica e prazerosa, para explorar um determinado ramo de conhecimento, além de trabalhar com algumas habilidades, como, por exemplo, destreza, associação de ideias e raciocínio lógico e indutivo, entre outras.

Os jogos em uso hoje em dia seguem o modelo comercial, pois são focados para o mercado e não estruturados pedagogicamente. O que se pretende com uma nova abordagem é aprimorar o sucesso obtido com o uso dos jogos em geral e, através de tecnologias específicas, adequar seus conceitos e incorporá-los ao processo educacional.

O jogo ajuda a criança a construir suas novas descobertas, desenvolve e enriquece sua personalidade e simboliza um instrumento pedagógico que leva o professor à condição de condutor, estimulador e avaliador da aprendizagem.

\section{A TECNOLOGIA DA INFORMAÇÃO}

Conforme O Brien (2004 p.6) "sistemas de informação é um conjunto organizado de pessoas, hardware, software, rede de comunicação e recursos de dados que coleta, transforma e dissemina informações em uma organização". O sistema recebe recursos de dados como entrada e os processa em produtos, como saída.

De acordo com Bastos (1998, p.24) vivendo em uma sociedade em constante mudança, onde o conhecimento é atualizado e reelaborado a todo instante e a escola enquanto formadora do cidadão crítico, deverá oportunizar estratégias inovadoras utilizando as mais diversas ferramentas disponíveis a fim de torná-lo capaz de atuar de maneira a resolver situações problema nessa sociedade de mudanças. As modernas tecnologias estão cada vez mais invadindo os muros das escolas e universidades. 
As Tecnologias da Informação e Comunicação (TICs) estão presentes no cotidiano da sociedade e na escola não é diferente. A própria Lei de Diretrizes e Bases da Educação Nacional (LDB) propõe uma prática educacional adequada à realidade do mundo, do mercado de trabalho e à integração do conhecimento (BRASIL, 1996).

A utilização efetiva das Tecnologias da Informação e Comunicação (TICs) nas instituições escolares segundo Ferreira et al (2013, p.20) é a base fundamental para a inserção do cidadão nesta sociedade tecnológica. Entretanto, verifica-se que se por um lado que os educandos estão abertos à era digital, prontos para a multimídia; por outro, os professores encontram diversas dificuldades para utilizá-las em sala de aula.

O uso das Tecnologias da Informação e Comunicação (TICs) assume um papel relevante, principalmente no campo da educação. Assim, uma formação de professores que possa prepará-los para o uso dessas novas tecnologias faz-se necessário por serem eles os atores principais para disseminar o conhecimento e proporcionar o desenvolvimento intelectual, social e afetivo dos seus alunos.

Nas palavras de Ferreira et al (2013, p.21), as Tecnologias da Informação e Comunicação (TICs) aplicadas à educação têm como premissa básica dinamizar o processo de ensino-aprendizagem, de modo a trabalhar o conteúdo por meio da digitalização e da comunicação em redes, mediada ou não por computadores, para a captação, transmissão e distribuição das informações como textos, imagens, vídeo e som.

No entanto, a efetivação desse processo depende em grande medida do saber utilizar adequadamente essas tecnologias no contexto da sala de aula, e, sobretudo, assegurando a construção do saber.

\subsection{A Potencialidade dos jogos digitais educacionais}

Uma das principais formas de acesso ao mundo da tecnologia para crianças e jovens é o jogo digital, pois geralmente o primeiro contato com equipamentos eletrônicos acontece por meio de um vídeo game (GROS, 2003, p. 19).

Os jogos digitais podem ser definidos como ambientes atraentes e interativos que capturam a atenção do jogador ao oferecer desafios que exigem níveis crescentes de destreza e habilidades. 
Desta forma de acordo com Gros (2003, p.19), os jogos digitais apontam os componentes básicos que são:

1) o papel ou personagem do jogador;

2) as regras do jogo;

3) metas e objetivos;

4) quebra-cabeças, problemas ou desafios;

5) história ou narrativa;

6) interações do jogador;

7) estratégias;

8) feedback e resultados.

Conforme relata Gros (2003, p.20), para serem utilizados como instrumentos educacionais os jogos devem conter ainda algumas características específicas para atender as necessidades vinculadas à aprendizagem.

Por isso os softwares educacionais, entre eles os jogos, devem possuir objetivos pedagógicos e sua utilização deve estar inserida em um contexto e em uma situação de ensino baseados em uma metodologia que oriente o processo, através da interação, da motivação e da descoberta, facilitando a aprendizagem de um conteúdo (PRIETO ET AL., 2005, p.25).

Quando preparados para o contexto educacional os jogos digitais podem receber diferentes nomenclaturas. As mais comuns são jogos educacionais ou educativos, jogos de aprendizagem ou jogos serious games ${ }^{1}$, sendo que alguns tipos de simuladores também podem ser considerados jogos educacionais.

De acordo com Prieto et al (2005, p. 27), quando se divulga a utilização de jogos educacionais, há um destaque para o poder motivador dessa mídia. Mas o potencial deles vai muito além do fator motivação, pois ajudam os estudantes a desenvolverem uma série de habilidades e estratégias e, por isso, começam a ser tratados como importantes materiais didáticos.

Os jogos colocam o aluno no papel de tomador de decisão e o expõe a níveis crescentes de desafios para possibilitar uma aprendizagem através da tentativa e erro.

Conforme relata Prieto et al (2005, p. 27), os professores reconhecem que os jogos, além de facilitarem a aquisição de conteúdo, contribuem também para o desenvolvimento de

\footnotetext{
${ }^{1}$ Jogos Sérios
} 
uma grande variedade de estratégias que são importantes para a aprendizagem, como resolução de problemas, raciocínio dedutivo e memorização.

Outros benefícios dos jogos e simuladores incluem a melhoria do pensamento estratégico e insight, melhoria das habilidades psicomotoras, desenvolvimento de habilidades analíticas e habilidades computacionais.

\subsection{O Uso dos jogos digitais educacionais}

Os jogos digitais já são utilizados em diferentes níveis de ensino, indo desde a préescola até cursos de graduação, especializações e cursos corporativos (SAVI, URIBRICHT, 2008, p.30).

De acordo com Savi; Uribricht (2008, p. 30), existem jogos que promovem ensinamentos básicos sobre linguagem e lógica para crianças que ainda estão em processo de alfabetização ou não sabem ler. Sendo assim, estes jogos servem para ensinar os alunos a começarem a utilizar o computador e a desenvolverem coordenação com o mouse e teclado.

Conforme relata Savi, Uribricht (2008, p. 31), esses jogos são simples e abordam o reconhecimento de letras e números, ensino de melodias em instrumentos virtuais, desafios de lógica e memória e jogos de línguas.

São exemplos desse tipo de jogos os programas Gcompris3 e Childsplay4, que apresentam conjuntos de jogos pré-escolares e de ensino fundamental. São softwares open source que podem ser livremente instalados e distribuídos (SAVI, URIBRICHT, 2008, p. 31).

Há também portais web como o IGuinho e Discovery Kids, similares aos exemplos anteriores, mas que disponibilizam os jogos na web. Com algumas buscas na internet é possível encontrar muitas fontes de jogos educacionais ou simuladores (SAVI, URIBRICHT, 2008, p. $31)$.

Um exemplo é o site do professor Romero Tavares da Silva, da Universidade Federal de Pernambuco - UFPE, que disponibiliza um conjunto de simuladores de física aplicáveis ao ensino médio. (SAVI, URIBRICHT, 2008, p.32).

De acordo com Savi, Uribricht (2008, p.32), dentro destes jogos são abordados temas como movimento retilíneo, energia, ondas e termodinâmica em pequenas aplicações interativas que permitem ao usuário inserir diferentes valores para variáveis e acompanhar o resultado nas animações do simulador. 
Ao final do procedimento pode-se verificar os resultados das experiências em gráficos que são gerados automaticamente.

Alguns jogos conforme relata Savi, Uribricht (2008, p.32) abordam a saúde e bem estar como temática central, são os health games. Um exemplo deste gênero é o Escape from Diabo, jogo em fase final de desenvolvimento, que tem o objetivo de prevenir a obesidade infantil e a diabetes, direcionando a atenção das crianças para a importância de uma alimentação saudável e a prática de exercícios.

Neste jogo, de acordo com os autores o usuário toma decisões e aprende como suas ações afetam a saúde dos personagens enquanto combate o vilão Rei Etes, que eliminou todas as oportunidades de exercícios de uma cidade e fornece quantidades ilimitadas de junkfoodpara a população. Manter um estilo de vida saudável é a única maneira de vencer o jogo e derrotar o Rei Etes e seus guardas.

\subsection{Desafios dos jogos digitais educacionais}

Apesar do potencial e benefícios, os jogos digitais educacionais ainda são pouco empregados e, para muitos professores, encontrar e utilizar bons jogos continua sendo um desafio (SAVI, URIBRICHT, 2008, p. 4).

Nas palavras de Savi, Uribricht (2008, p.34), isso ocorre porque muitos jogos educacionais têm feito uso limitado de princípios pedagógicos e acabam sendo ignorados pelos educadores por agregarem pouco valor às aulas.

Nesse sentido, os autores comentam que empresas e especialistas no desenvolvimento de games, que não possuem conhecimentos específicos sobre teoria e prática do uso de jogos em ambientes de aprendizagem, criam produtos educacionais que são atraentes e divertidos, mas falham em relação aos objetivos de aprendizagem.

Por outro lado, jogos desenvolvidos por educadores com um viés mais acadêmico, com pouco conhecimento da arte, ciência e cultura de projetos de jogos, na maioria dos casos resultam em artefatos pouco divertidos que não conseguem atrair a atenção dos alunos (SAVI, URIBRICHT, 2008, p.34).

Os jogos educacionais devem atender a requisitos pedagógicos, mas também é preciso tomar cuidado para não tornar o jogo somente um produto didatizado, fazendo-o perder seu caráter prazeroso e espontâneo. 
É necessário encontrar a sinergia entre pedagogia e diversão nos jogos educacionais, mas isso tem demonstrado ser uma tarefa difícil.

De acordo com Savi, Uribrict (2008, p.37), atualmente muitos jogos e softwares educacionais não atingem as expectativas dos educadores e alunos e algumas das principais razões são: A maioria dos jogos educacionais é muito simples em relação aos vídeo games comerciais de competição e não atendem as expectativas dos alunos mais exigentes, já acostumados com a sofisticação dos jogos de entretenimento.

Nas palavras de Savi, Uribrict (2008, p.37) a criação de jogos educacionais mais sofisticados também é afetada pelos custos envolvidos no desenvolvimento, pois esse é um tipo de software complexo que normalmente demanda o emprego de várias áreas da computação, como banco de dados, redes de computadores, computação gráfica e estrutura de dados.

Portanto, torna-se difícil desenvolver jogos educacionais com qualidade técnica, artística e pedagógica sem o envolvimento de uma equipe multidisciplinar para o projeto, que resulta em custos significativos para recursos humanos (SAVI, URIBRICHT, 2008, p.37).

Para o desenvolvimento de jogos pode-se fazer uso de duas plataformas de autoria multimídia, a fim de selecionar a que oferece maiores vantagens de uso, sendo elas as plataformas: Construct 2 e Stencyl. ${ }^{2}$

As plataformas de autoria multimídia são comumente empregadas no desenvolvimento de jogos educativos, por fornecerem técnicas relevantes e ágeis.

Em meio às semelhanças entre ambas e tendo sido verificadas as vantagens $\mathrm{e}$ desvantagens de cada uma, a plataforma Stencyl foi escolhida devido a fatores como: o seu conceito de programação drag-and-drop, sua interface intuitiva e atraente, à forma de estruturação e organização dos componentes dos jogos, o fornecimento de exemplos de jogos criados a partir da mesma, conexão com um repositório para aquisição de recursos compartilhados gratuitamente, e principalmente, pelo fato de não restringir recursos na versão gratuita.

\section{RESULTADOS E DISCUSSÕES}

De acordo com a uma pesquisa realizada verbalmente em algumas escolas da rede municipal de ensino, pode-se verificar que os professores e direção sentem falta de jogos

\footnotetext{
${ }^{2}$ Plataforma de jogos sem necessidade de programação feita para Androids
} 
especializados para seus alunos, principalmente para alunos portadores de necessidades especiais.

Eles relatam que os jogos poderiam auxiliá-los na construção de diversas atividades e também ajudaria com os alunos que possuem dificuldade de aprendizagem.

Isso pode ser observado no gráfico 1.

\section{Gráfico 1 - Utilização de Jogos em Sala de Aula}

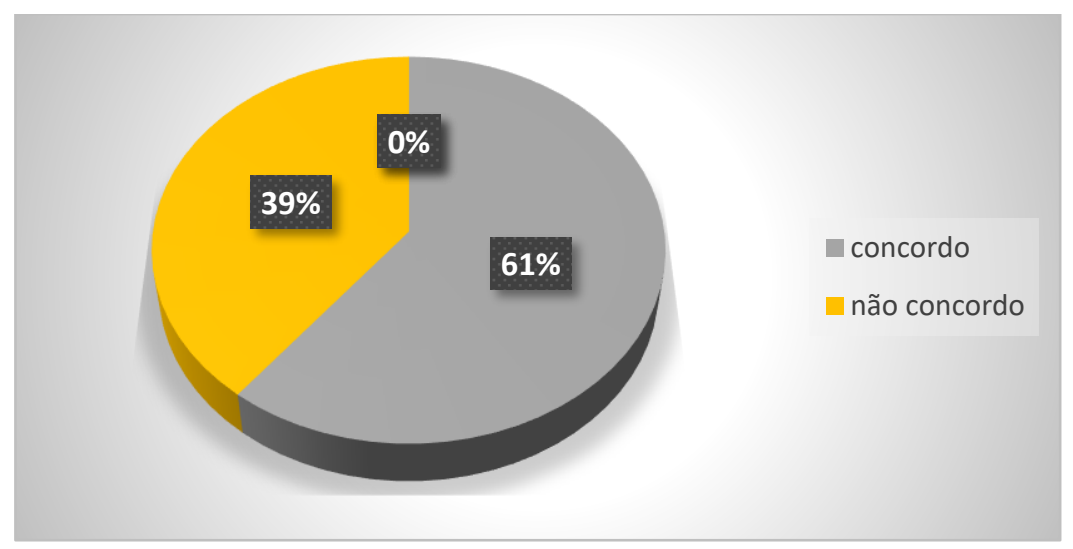

Fonte: Os Autores

Através do gráfico 1 pode-se perceber que os professores têm sim interesse no uso dos jogos em sala de aula para um melhor aproveitamento e rendimento de suas atividades.

A aprendizagem que é construída em interações com os jogos não é mera cópia mecânica das situações vivenciadas, mas uma ressignificação que os jogadores fazem das imagens e ações presentes no conteúdo dos jogos eletrônicos mediante seus modelos de aprendizagem construídos ao longo de sua estruturação como sujeitos.

Desta forma acredita-se que um projeto de software educacional precisa de definições e requisitos que vão além do contexto onde este deverá ser usado, mas perpassam decisões sobre conteúdos, que envolvam a seleção, escolha dos tipos de conteúdo, as sequências, a organização visual e didática assim como a adaptação aos diferentes tipos de usuários.

Os softwares educacionais como pode-se observar, devem ser um instrumento que amplie as possibilidades de conhecimento do aluno, à medida que considere necessária a articulação dos conceitos espontâneos (conhecimentos prévios) com os conhecimentos que o educador deseja levar o aluno a construir. 


\section{CONSIDERAÇÕES FINAIS}

Os jogos eletrônicos se configuram como parte constituinte do espectro cultural dos dias de hoje, sendo responsáveis pela criação e manutenção de símbolos que acompanham a sociedade desde que deixaram de ser meros brinquedos encerrados em laboratórios universitários para tornar-se uma das indústrias mais rentáveis no panorama econômico mundial atual.

Observar como os jogos eletrônicos se tornaram um diferencial em mais uma plataforma não é de todo surpreendente. As questões que foram levantadas dizem respeito ao modo pelo qual, ao adicionar um elemento diferencial, sendo este os vários modos do jogo, a própria estrutura interacional do site vem a sofrer modificações.

Os jogos digitais educativos se comportam como um recurso didático que pode trazer uma série de benefícios para as práticas de ensino e de aprendizagem e, por estarem vinculados ao uso de computadores e outros dispositivos, reforçam a ideia de se comportarem como um recurso acessível e que cumpre o objetivo de disseminar informação.

\section{REFERÊNCIAS}

BASTOS, João Augusto de Souza. Educação e Tecnologia: conceitos, características e perspectivas. Curitiba: CEFET, 1998.

BRASIL. Secretaria de Educação Fundamental. Parâmetros curriculares nacionais: geografia / Secretaria de Educação Fundamental. - Brasília : MEC/ SEF, 1996.

FERREIRA, A. M.; SILVA, T. P.; BRUZZON, M. J. S. N.; XAVIER, P. S. O uso das TICs como ferramenta no ensino de geografia In: Seminário PIBID UNEMAT, 5a . (JC), 2013, Cáceres/MT. Anais... Cáceres/MT: Pró-Reitoria de Ensino de Graduação PROEG, 2013.

GROS, Begoña. The impactof digital games in education. FirstMonday, v. 8, n. 7, jul. 2003. Disponível em: http://www.firstmonday.org/ojs/index.php/fm/issue/view/159. Acesso em: 20mar. 2018.

MORAN, José Manuel. Gestão inovadora da escola com tecnologias.2003. Disponível em: <http://www.eca.usp.br/prof/moran/gestao.htm>. Acesso em: 25 mar. 2018.

O’BRIEN, J. A. Sistemas de informação e as decisões gerenciais na era da Internet. 2. ed. São Paulo: Saraiva 2004. 
PRIETO, Lilian Medianeira et al. Uso das Tecnologias Digitais em Atividades Didáticas nas Séries Iniciais.Renote: revista novas tecnologias na educação, Porto Alegre, v. 3, n. 1, p.111, maio 2005. Disponível em:

http://www.cinted.ufrgs.br/renote/maio2005/artigos/a6_seriesiniciais_revisado.pdf. Acesso em: 25 mar. 2018.

SAVI, Rafael. UBRICHT, Vania Ribas. Jogos Digitais Educacionais: Benefícios e Desafios. Revista Novas Tecnologias na Educação, V. 6 No 2, Dezembro, 2008. 